\title{
Omega-3 Polyunsaturated Fatty Acids in Youths with Attention Deficit Hyperactivity Disorder: a Systematic Review and Meta-Analysis of Clinical Trials and Biological Studies
}

\author{
Jane Pei-Chen Chang, ${ }^{*, 2,3}$, Kuan-Pin Su' ${ }^{1,2,3,4}$, Valeria Mondelli' and Carmine M Pariante' \\ 'Department of Psychological Medicine, Institute of Psychiatry, Psychology and Neuroscience, King's College London, London, UK; '2 Department of \\ Psychiatry, China Medical University Hospital, Taichung, Taiwan; ${ }^{3}$ Department of Psychiatry, College of Medicine, China Medical University, \\ Taichung, Taiwan; ${ }^{4}$ Brain Disease Research Center, China Medical University Hospital, Taichung, Taiwan
}

\begin{abstract}
The role of omega-3 polyunsaturated fatty acids (omega-3 or n-3 PUFAs) in the pathogenesis and treatment of children and adolescents with attention deficit hyperactivity disorder (ADHD) is unclear. A systematic review followed by meta-analysis was conducted on: (I) randomized controlled trials (RCTs) assessing the effects of $n-3$ PUFAs on clinical symptoms and cognition in children and adolescent with ADHD; and (2) case-control studies assessing the levels of $n-3$ PUFAs in blood and buccal tissues of children and adolescents with ADHD. In seven RCTs, totalling $n=534$ randomized youth with ADHD, $n-3$ PUFAs supplementation improves ADHD clinical symptom scores $(g=0.38, p<0.0001)$; and in three RCTs, totalling $n=214$ randomized youth with ADHD, $n-3$ PUFAs supplementation improves cognitive measures associated with attention $(g=1.09, p=0.00 \mathrm{I})$. Moreover, children and adolescents with ADHD have lower levels of DHA (seven studies, $n=412, g=-0.76, p=0.0002$ ), EPA (seven studies, $n=468, g=-0.38, p=0.0008$ ), and total $n-3$ PUFAs (six studies, $n=396, g=-0.58, p=0.000 \mathrm{I}$ ). In summary, there is evidence that $n-3$ PUFAs supplementation monotherapy improves clinical symptoms and cognitive performances in children and adolescents with ADHD, and that these youth have a deficiency in $n-3$ PUFAs levels. Our findings provide further support to the rationale for using n-3 PUFAs as a treatment option for ADHD.

Neuropsychopharmacology (2018) 43, 534-545; doi:I0.1038/npp.2017.160; published online 23 August 2017
\end{abstract}

\section{INTRODUCTION}

Deficiency in omega-3 polyunsaturated fatty acids (n-3 PUFAs) has recently been investigated as a potential pathogenetic mechanism in ADHD (Stevens et al, 1995). Although current pharmacotherapies, such as methylphenidate and atomoxetine, are able to improve ADHD symptoms (The MTA Cooperative Group, 1999; Quintana et al, 2007), there is still about $20-40 \%$ of patients with ADHD who do not benefit from these medications (Pliszka et al, 2006). Therefore, novel treatments with clear efficacy and measurable biological mechanisms are essential. At cognitive levels, ADHD has been suggested to be a disorder involving an impaired inhibition control system (Barkley, 1997) and a disrupted feedback of the rewarding and motivational system (Barkley, 1997), and n-3 PUFAs have been associated with cognitive function and learning (Milte et al, 2011), including in patients with ADHD (Sinn et al, 2008; Vaisman et al,

*Correspondence: Dr JP-C Chang, Institute of Psychiatry, Psychology \& Neuroscience, King's College London, The Maurice Wohl Clinical Neuroscience Institute, G.33.72, Cutcombe Road, London SE5 9RT, UK, Tel: +44 (0)20 7848 053I, Fax: +44 (0)20 78485408 ,

E-mail: peko80@gmail.com

Received 28 April 2017; revised 3 July 2017; accepted 18 July 2017; accepted article preview online 25 July 2017
2008; Voigt et al, 2001). Hence, $n$-3 PUFAs may be considered one of such novel treatments.

Several lines of evidence support the importance of $n-3$ PUFAs in brain disorders (Hibbeln et al, 2007; Su et al, 2008; Su et al, 2014). The $n$-3 PUFAs series include docosahexaenoic acid (DHA or 22:6n-3) and eicosapentaenoic acid (EPA or $20: 5 n-3$ ), which are essential fatty acids (EFA) that cannot be efficiently synthesized by the human body and have to be obtained through dietary intake. EPA and DHA have an anti-inflammatory action via inhibition of free radical generation and oxidant stress (Das, 2006), and have also been shown to regulate neurotransmitter and immune functions via the modulation of lipid rafts signalling platforms on the cell membrane (Chang and Su, 2010). Moreover, $n$-3 PUFAs also improve symptoms of depression (Lin and Su, 2007; Su et al, 2003; Su et al, 2008; Su et al, 2014) and Alzheimer's Disease (Chiu et al, 2008).

There is promising evidence that $n-3$ PUFAs may be relevant to ADHD. In epidemiological studies, children of mothers who have lower seafood intake during pregnancy are at risk of suboptimal outcomes for prosocial behaviors, fine motor coordination, verbal communication and social development (Hibbeln et al, 2007). Moreover, we have shown that children with ADHD have greater severity of EFA deficiency, a clinical syndrome associated with insufficient fatty acid levels and comprising symptoms such as dry 
and scaly skin, eczema, and dry eyes (Chang et al, 2016). In addition, EFA dietary deficiency in children with ADHD correlates negatively with plasma DHA levels (Stevens et al, 1995), and we have recently shown that EFA deficiency positively correlates with ADHD symptoms (Chang et al, 2016). However, several case-control studies have reported no dietary differences, or even higher dietary PUFAs intake, in ADHD (Chen et al, 2004; Colter et al, 2008; Gow et al, 2013; Stevens et al, 1995). Interestingly, some clinical trials with n-3 PUFAs supplementation in ADHD have shown improvement in clinical symptoms (Manor et al, 2012; Perera et al, 2012; Richardson and Puri, 2002) and cognitive performances (Sinn et al, 2008; Vaisman et al, 2008; Voigt et al, 2001), but others have found no beneficial effects (Widenhorn-Muller et al, 2014). Hence our decision to conduct the present meta-analysis.

In terms of PUFAs levels, lower red blood cells (RBCs) PUFAs (Stevens et al, 1995) and a higher $n-6 / n-3$ ratio (Stevens et al, 2003) have been reported in ADHD, and lower $n$-3 PUFAs levels are positively associated with the severity of ADHD symptoms in children (Colter et al, 2008; Stevens et al, 2003). However, some studies could not replicate the differences in $n-3$ PUFAs levels between children with ADHD and controls (Gow et al, 2013; Stevens et al, 2003). Again, this inconsistency in the literature has prompted us to conduct the present meta-analysis.

Although there were previous meta-analyses on this topic (Cooper et al, 2015; Gillies et al, 2012; Hawkey and Nigg, 2014; Puri and Martins, 2014; Sonuga-Barke et al, 2013), their findings might be confounded by heterogeneity in the clinical samples, including both children and adult subjects (Hawkey and Nigg, 2014) or subjects with diagnosis other than ADHD (Cooper et al, 2015; Puri and Martins, 2014), as well as by the inclusion of non-parallel trials (Hawkey and Nigg, 2014; Puri and Martins, 2014) as well as mixed supplementation interventions including $n-3$ PUFAs together with vitamins and nutrients (Gillies et al, 2012; Sonuga-Barke et al, 2013). To address these issues, we have performed a systematic review and meta-analyses to examine both the efficacy of $n$-3 PUFAs supplementation and the levels of $n-3$ PUFAs, specifically in young (children and adolescents) subjects with ADHD. We have also examined the factors potentially modulating these findings, such as the EPA and DHA dosages in the supplementations trials, and the source tissue (RBCs, plasma, buccal cells) for the measurements of $n$-3 PUFAs levels.

\section{MATERIALS AND METHODS}

We conducted a systematic review and meta-analysis in accordance with the Preferred Reporting Items for Systematic Reviews and Meta-Analysis (PRISMA) guidelines (Moher et al, 2009).

\section{Literature Search}

To identify eligible studies for this meta-analysis, a computerized search was performed for all publications available up to 31st March 2017 through Cochrane Central Register of Controlled Trials, Embase, Ovid Medline, PsychInfo, limited to literature in English and human studies. The search terms used are listed in Supplementary
Table S1. References of eligible trials and appropriate reviews were searched for additional citations. Unpublished or ongoing trials were searched on ClinicalTrials.gov website and authors contacted to request relevant data. Our initial search identified 4415 studies (Figure 1).

\section{Inclusion Criteria of Studies in the Meta-Analysis}

The characteristics of included articles are described in Table 1, Supplementary Tables S2 and S3.

n-3 PUFAs supplementations and clinical symptoms. Our criteria were: (1) studies were randomized, double-blind, placebo-controlled trials of $n-3$ PUFAs supplementation with DHA and EPA alone or in combination; (2) participants were school-aged children (4-12 years) and adolescents (13-17 years) who had a diagnosis of ADHD; (3) the study measured clinical symptoms of ADHD as reported by parents; (4) the data allowed to calculate an effect size; and (5) the publications were in peer-reviewed journals.

We identified eight studies (Bos et al, 2015; Gustafsson et al, 2010; Manor et al, 2012; Perera et al, 2012; Richardson and Puri, 2002; Sinn et al, 2008; Vaisman et al, 2008; Widenhorn-Muller et al, 2014), totalling 628 subjects: 366 received $n$-3 PUFAs and 262 received placebo. Seven studies were included in the meta-analysis for total ADHD clinical symptoms totalling 534 subjects: 318 received $n$-3 PUFAs and 216 received placebo. Seven studies were included in the meta-analysis for inattention clinical symptoms (Bos et al, 2015; Gustafsson et al, 2010; Manor et al, 2012; Perera et al, 2012; Richardson and Puri, 2002; Sinn et al, 2008; Widenhorn-Muller et al, 2014), totalling 590 subjects: 348 received $n-3$ PUFAs and 242 received placebo. Six studies were included in the meta-analysis for hyperactivity clinical symptoms (Gustafsson et al, 2010; Manor et al, 2012; Perera et al, 2012; Richardson and Puri, 2002; Sinn et al, 2008; Widenhorn-Muller et al, 2014), totalling 551 subjects: 328 received $n$-3 PUFAs and 223 received placebo.

n-3 PUFAs supplementation and cognitive performance. Our criteria were: (1) studies were randomized, doubleblind, placebo-controlled trials of $n-3$ PUFAs supplementation with DHA and EPA alone or in combination; (2) participants were school-aged children (4-12 years) and adolescents (13-17 years) who had a diagnosis of ADHD; (3) the studies measured cognitive performance defined as omission errors, commission errors, forward memory, backward memory, and information processing; (4) the data allowed to calculate an effect size; and (5) the publications were in peer-reviewed journals.

We identified four studies (Sinn et al, 2008; Vaisman et al, 2008; Voigt et al, 2001; Widenhorn-Muller et al, 2014), totalling 309 subjects: 178 received $n-3$ PUFAs and 131 received placebo. Three studies were included in the metaanalysis for omission errors (Sinn et al, 2008; Vaisman et al, 2008; Voigt et al, 2001), totalling 214 subjects: 134 received $n-3$ PUFAs and 80 received placebo. Two studies were included in the meta-analysis for commission errors totalling 85 subjects: 43 received $n$-3 PUFAs and 42 received placebo. Two studies were included in the meta-analysis for memory (Sinn et al, 2008; Widenhorn-Muller et al, 2014), totalling 224 subjects: 
137 received $n-3$ PUFAs and 87 received placebo. Four studies were included in the meta-analysis for information processing (Sinn et al, 2008; Vaisman et al, 2008; Voigt et al, 2001; Widenhorn-Muller et al, 2014), totalling 309 subjects: 178 received $n$-3 PUFAs and 131 received placebo.

n-3 PUFAs levels. Our criteria were: the studies (1) measured levels of DHA, EPA, AA, total $n-3$, or total $n-6$; and (2) used samples from RBCs membrane, blood phospholipids, and cholesteryl esters, or buccal cells; (3) participants were school-aged children (4-12 years) and adolescents (13-17 years) who had a diagnosis of ADHD; (4) the data allowed to calculate an effect size; and (5) the publications were in peer-reviewed journals.

Nine studies were included in the meta-analysis on $n-3$ PUFAs levels (Bos et al, 2015; Chen et al, 2004; Colter et al, 2008; Germano et al, 2007; Gow et al, 2009; Gow et al, 2013; Mitchell et al, 1987; Stevens et al, 2003; Stevens et al, 1995), totalling 558 subjects: 297 youths with ADHD and 261 controls. Eight studies were included in the meta-analysis for DHA level (Bos et al, 2015; Chen et al, 2004; Colter et al,
2008; Germano et al, 2007; Gow et al, 2009; Mitchell et al, 1987; Stevens et al, 2003; Stevens et al, 1995), totalling 486 subjects: 268 youth with ADHD and 218 controls. Eight studies were included in the meta-analysis for EPA levels (Chen et al, 2004; Colter et al, 2008; Germano et al, 2007; Gow et al, 2009; Gow et al, 2013; Mitchell et al, 1987; Stevens et al, 2003; Stevens et al, 1995), totalling 542 subjects: 285 youth with ADHD and 257 controls. Seven studies were included in the meta-analysis for total $n$-3 PUFAs levels (Bos et al, 2015; Chen et al, 2004; Colter et al, 2008; Germano et al, 2007; Gow et al, 2013; Stevens et al, 2003; Stevens et al, 1995), totalling 470 subjects: 250 youth with $\mathrm{ADHD}$ and 220 controls. Eight studies were included in the meta-analysis for AA levels (Bos et al, 2015; Chen et al, 2004; Colter et al, 2008; Germano et al, 2007; Gow et al, 2013; Mitchell et al, 1987; Stevens et al, 2003; Stevens et al, 1995), totalling 567 subjects: 298 youth with ADHD and 269 controls. Eight studies were included in the meta-analysis for total n-6 PUFAs levels (Bos et al, 2015; Chen et al, 2004; Colter et al, 2008; Germano et al, 2007; Gow et al, 2009; Gow et al, 2013; Stevens et al, 2003; Stevens et al, 1995), totalling 499 subjects: 270 youth with

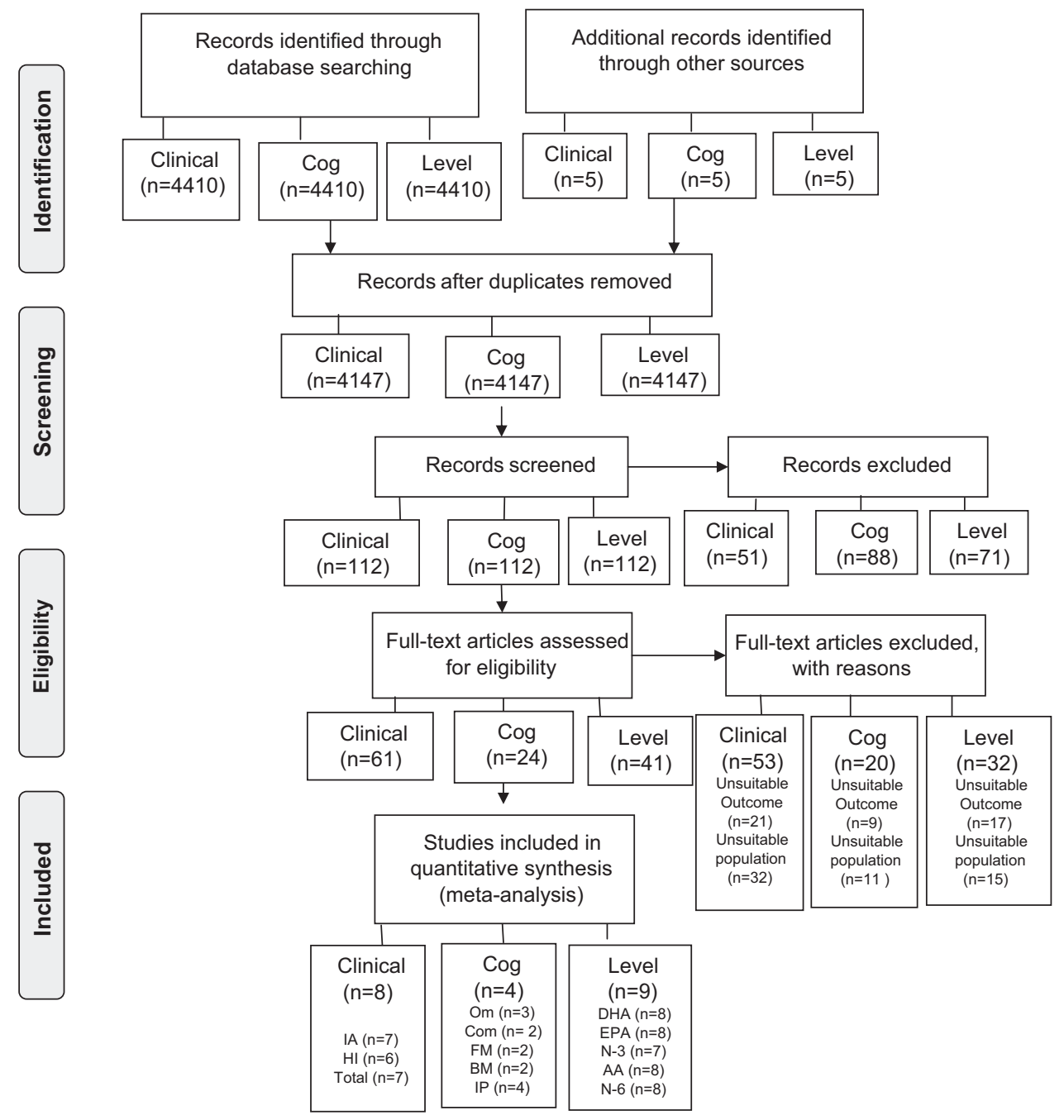

Figure I PRISMA Flow Diagram. AA, arachidonic acid; BM, backward memory; Cog, cognition, Com, commission errors; DHA, docosahexaenoic acid; EPA, eicosapentaenoic acid; FM, forward memory; HI, hyperactivity-impulsivity; IA, inattention; IP, information processing; N-3, omega-3; N-6, omega-6; Om, omission errors. 
ADHD and 229 controls. If a study had measurements of both RBCs and plasma levels for PUFAs (DHA, EPA, AA, $n-3, n-6)$, only measurement of RBCs level were included in the meta-analysis, since plasma levels reflect more recent fluctuations (eg, days) in phospholipids while RBCs levels reflect more long term changes (eg, months).

Studies that included and re-analyzed the same data set as previously published studies were not regarded as independent, and only the study with the highest number of participants was included. See Figure 1 for the flow chart showing the selection of included studies.

\section{Meta-Analytic Methods}

In our analysis, the primary outcomes were comparisons of (1) clinical symptoms and cognitive performance in RCTs (omission errors, commission errors, memory, and information processing) between $n-3$ and placebo groups; and 2) levels of DHA, EPA, AA, total n-3 PUFAs and total n-6 PUFAs, between ADHD and controls.

For each identified study, the effect size (ES) expressing the difference in clinical symptoms and cognitive performance between $n-3$ and placebo group, or the difference in the PUFAs levels between ADHD and controls, were described as standardized mean difference (SMD) on the basis of Hedge's adjusted $g$, in which a value greater than 0 indicated n-3 PUFAs were superior than placebo, or levels were higher in ADHD subjects. When these data could not be retrieved from the publications, we contacted the authors to acquire the data of derived ES from other measures of variability. The results of individual studies were synthesized by the random effects model (Shadish, 1994), but which ESs were pooled and $95 \%$ confidence intervals (CIs) were calculated. The significance of the pooled effect size was determined by the $z$-test. Sensitivity analyses were performed to determine whether any individual study was responsible for the significant results. Moreover, each study was individually removed and the significance was retested. The $I^{2}$ statistic assessed heterogeneity between studies. Publication bias was assessed using the Egger regression asymmetry tests (and inspection of the regression asymmetry plot) and the Begg adjusted rank correlation test. Meta-analyses were conducted by applying STATA (Stata Corp, 2009) and Forest plots were created by using Review Manager 5.3 (Cochrane Collaboration, 2014). Two-sided $p$ values $<0.05$ were considered statistically significant.

\section{RESULTS}

\section{n-3 PUFAs Improves Clinical Symptoms in ADHD}

The major finding of our study is that n-3 PUFAs supplementation significantly improves parental reports of total symptom scores (7 studies, $n=534, g=0.38, p<0.0001$ ), inattention ( 7 studies, $n=590, g=0.42, p<0.0001$ ), and hyperactivity (6 studies, $n=551, g=0.48, p=0.04$ ) (see Figure 2). We also did a subanalysis looking at effects of $n-3$ PUFAs using two specific measurements, the Conner's cognition subscale (Richardson and Puri, 2002; Sinn et al, 2008) and the Conner's DSM-IV inattention subscale (Manor et al, 2012; Richardson and Puri, 2002; Sinn et al, 2008): n-3 PUFAs have a significant effect on both scores (2 studies, $n=159, g=0.49$, $p=0.01 ; 3$ studies, $n=306, g=0.36, p=0.007$, respectively). For both inattention (Figure 2a) and total ADHD score (Figure 2c), these effects are significant also in the subgroup analyses testing separately studies with EPA dosage of $500 \mathrm{mg} /$ day or greater, and studies with EPA dosage less than $500 \mathrm{mg}$. However, for hyperactivity (Figure 2b), only studies with EPA dosage of $500 \mathrm{mg}$ per day or greater (Gustafsson et al, 2010; Perera et al, 2012; Widenhorn-Muller et al, 2014) show a

Table I Characteristics of Studies Included in the Meta-Analysis for Effects of n-3 PUFAs on ADHD Clinical Symptoms

\begin{tabular}{|c|c|c|c|c|c|c|}
\hline Studies & $\begin{array}{l}\text { n-3 PUFAs, n } \\
\text { (male, \%) }\end{array}$ & $\begin{array}{l}\text { Placebo, } n \\
\text { (male, \%) }\end{array}$ & $\begin{array}{l}\text { n-3 PUFAs } \\
\text { (dosage) }\end{array}$ & $\begin{array}{l}\text { Age, mean (SD), } \\
\text { or age range }\end{array}$ & Country & $\begin{array}{l}\text { Clinical Symptom } \\
\text { Measurements }\end{array}$ \\
\hline $\begin{array}{l}\text { Richardson and Puri, } \\
2002\end{array}$ & 15 (NS) & 15 (NS) & $\begin{array}{l}\text { EPA ( } 186 \mathrm{mg}) \\
\text { DHA (480 mg) }\end{array}$ & $8-12$ & UK & CPRS-L; Conner's ADHD \\
\hline Sinn et al, 2008 & $91(75.6)$ & $38(73.7)$ & $\begin{array}{l}\text { EPA (93 mg) } \\
\text { DHA (29 mg) }\end{array}$ & $\begin{array}{l}n-3: 9.38(1.9) \\
P: 9.47(1.8)\end{array}$ & Australia & CPRS Conner's ADHD Index \\
\hline Vaisman et al, 2008 & $18(83.3)$ & $21(71.4)$ & $\begin{array}{l}\text { EPA (I } 53 \mathrm{mg}) \\
\text { DHA (96 mg) }\end{array}$ & $\begin{array}{l}n-3: 9.17(1.3) \\
\quad P: 9.3(1.4)\end{array}$ & Israel & Abbreviated CRS \\
\hline Gustafsson et al, 2010 & 46 (NS) & 46 (NS) & $\begin{array}{l}\text { EPA (500 mg) } \\
\text { DHA (2.7 mg) }\end{array}$ & $7-12$ & Sweden & CRS \\
\hline Perera et al, 2012 & $48(70.8)$ & $46(76.1)$ & EPA (560 mg) & NS & Sri Lanka & SNAP-IV \\
\hline Manor et al, 2012 & $100(72)$ & $47(68)$ & $\begin{array}{l}\text { EPA (80 mg) } \\
\text { DHA (40 mg) }\end{array}$ & 9.2 & Israel & CTRS, CPRS, SDQ, CHQ-PF50 \\
\hline $\begin{array}{l}\text { Widenhorn-Muller et al, } \\
2014\end{array}$ & $46(76)$ & $49(79)$ & $\begin{array}{l}\text { EPA (600 mg) } \\
\text { DHA (I } 20 \text { mg) }\end{array}$ & $8.91(1.4)$ & Germany & DISYPS-II, CBCL, TRF \\
\hline Bos et al, 2015 & $19(100)$ & $19(100)$ & $\begin{array}{l}\text { EPA (650 mg) } \\
\text { DHA (640 mg) }\end{array}$ & $10.3(2.0)$ & $\mathrm{NE}$ & SWAN, CBCL, TRF \\
\hline
\end{tabular}

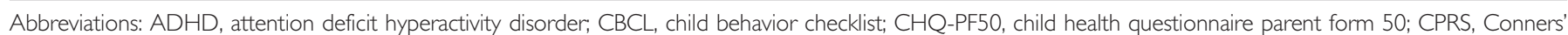

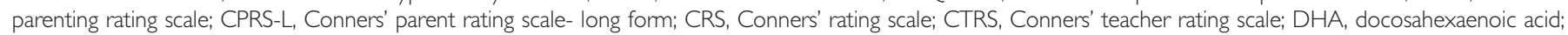

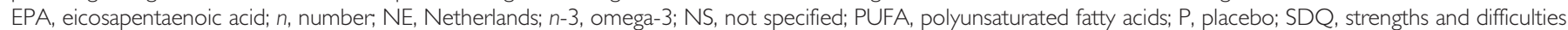

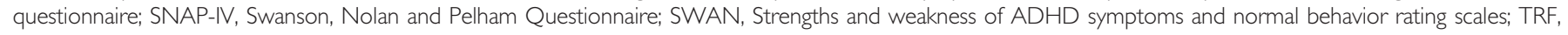
teacher report form; UK, United Kingdom; yrs, years. 
Omega-3 in youth with ADHD

JP Chang et al

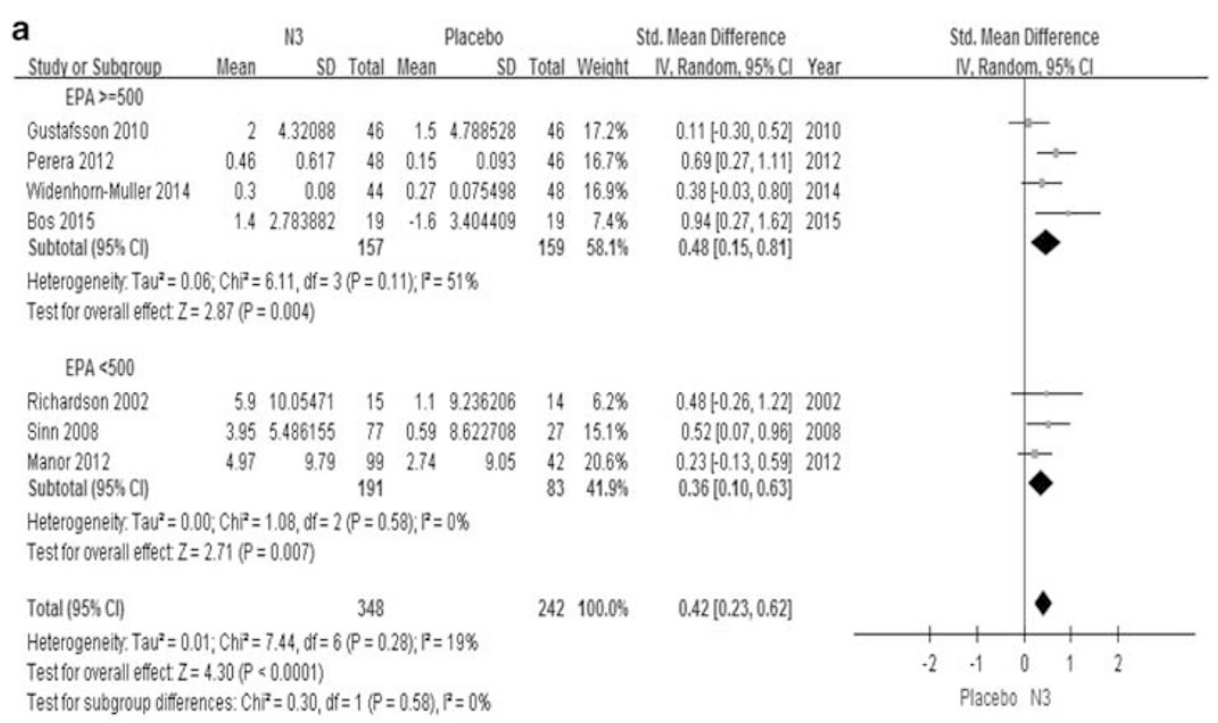

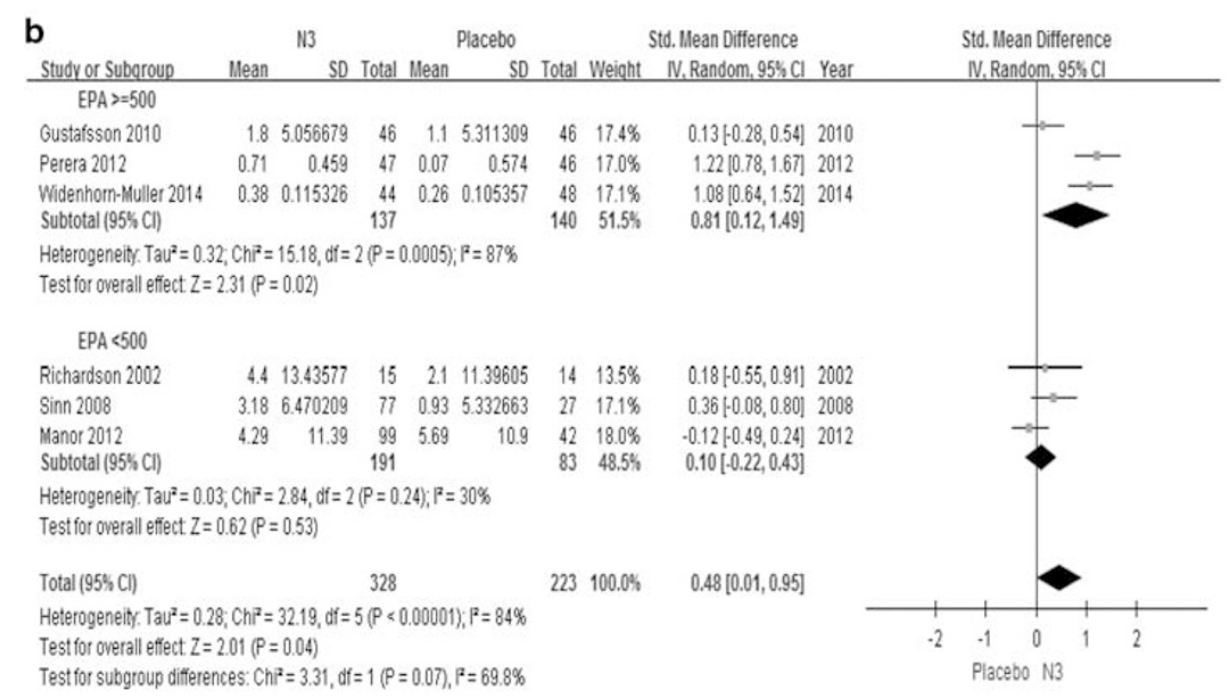

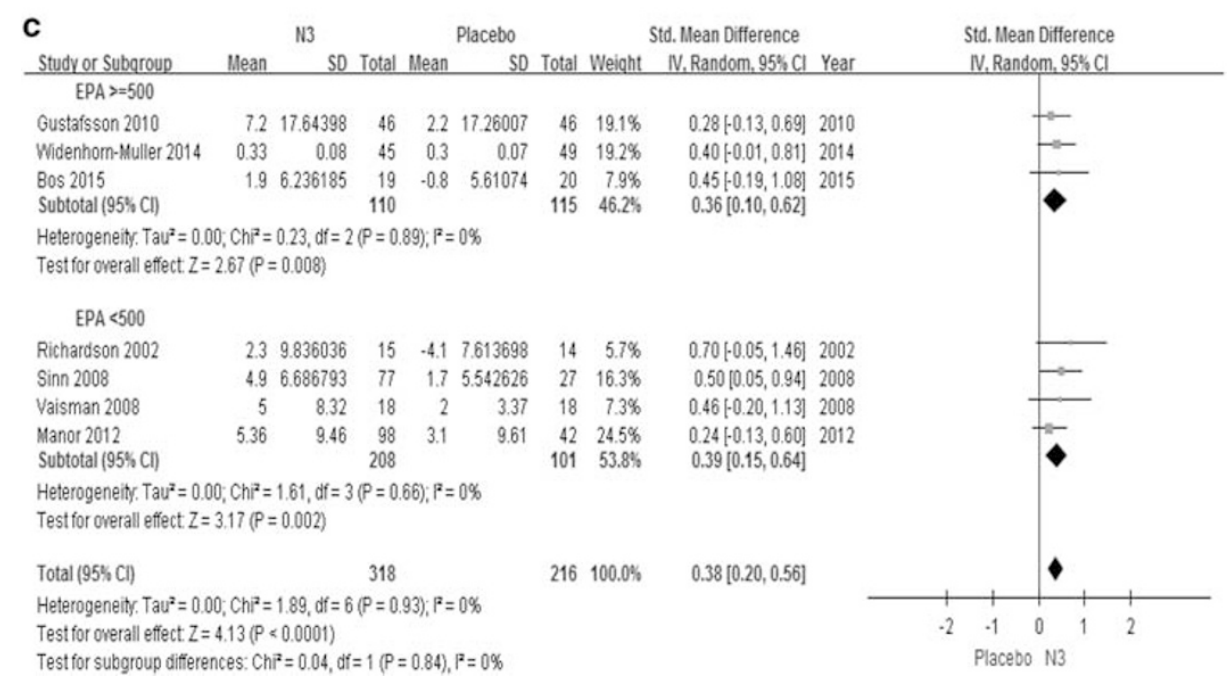

Figure 2 Forest plots showing effect sizes (Hedges's g) and 95\% confidence intervals (Cls) from individual studies and pooled results comparing ADHD clinical symptoms, (a) inattention symptom scores, (b) hyperactivity symptom scores, (c) total ADHD symptom scores, between n3 and placebo group. ADHD, attention deficit hyperactivity disorder; Cl, confidence interval; Std, standard; EPA, eicosapentaenoic acids; DHA, docosahexaenoic acids; N3, n-3 or omega-3 polyunsaturated fatty acids; $>=500$, clinical trials with EPA dosage $>500 \mathrm{mg} ;<500$, clinical trials with EPA dosage $<500 \mathrm{mg}$. 

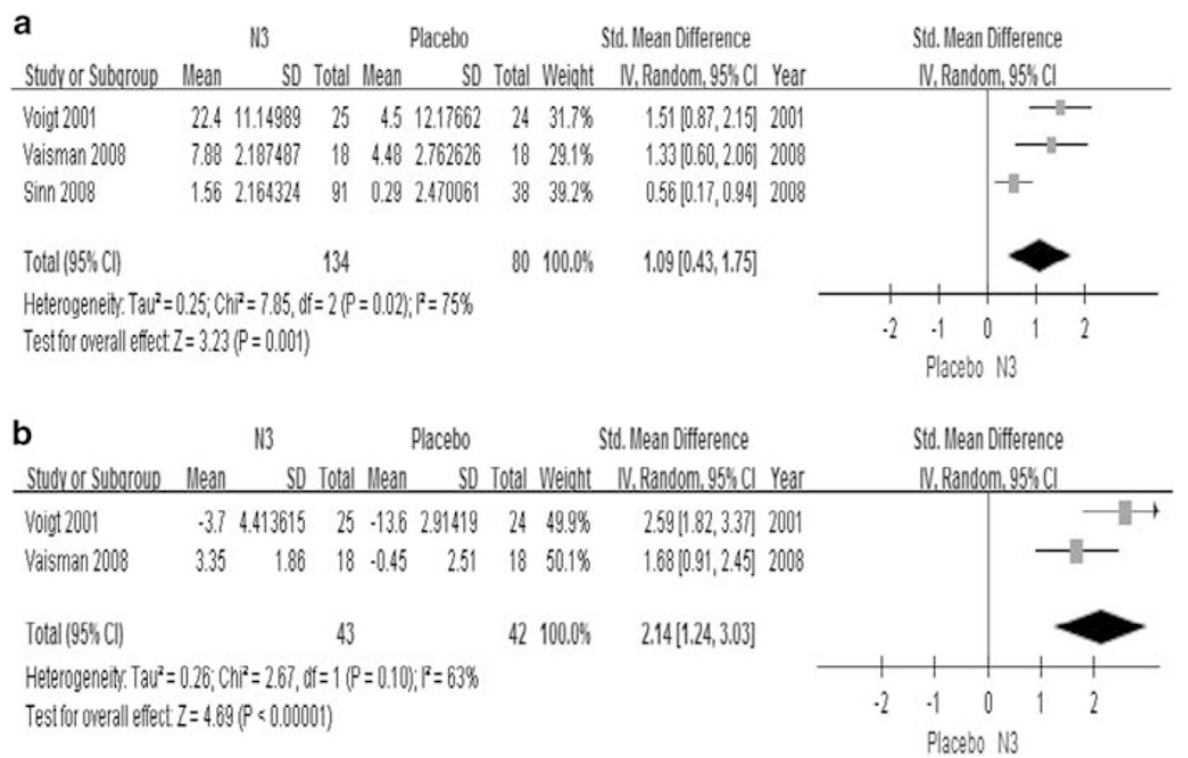

Figure 3 Forest plots showing effect sizes (Hedges's g) and 95\% confidence intervals (Cls) from individual studies and pooled results comparing cognitive function, (a) omission and (b) commission, between n-3 group and placebo group. Cl, confidence interval; N3, n-3 or omega-3 polyunsaturated fatty acid; Std, standard.

significant effect, but not those with smaller dosages (Manor et al, 2012; Richardson and Puri, 2002; Sinn et al, 2008). Interestingly, only one study (Perera et al, 2012) in our metaanalysis used EPA as the sole source for omega-3 supplementation, and showed a significant effect for both inattention $(n=93, g=0.69, p=0.001)$ and hyperactivity symptoms $(n=93, g=1.22, p<0.00001)$.

Of note, $n-3$ PUFAs have no significant effect on teacher's reports of inattention, hyperactivity or total scores (Gustafsson et al, 2010; Manor et al, 2012; WidenhornMuller et al, 2014) (3 studies, $n=334, p=0.20$ ).

\section{n-3 PUFAs Improves Cognitive Performance in ADHD}

The second main finding of our study is that $n-3$ PUFAs supplementation is superior to placebo in terms of cognitive performance for omission errors (3 studies, $n=214, g=1.09$, $p=0.001$ ) and commission errors (2 studies, $n=85, g=2.14$, $p<0.00001$ ) (Figure 3), but not forward memory (2 studies, $n=224, p=0.66$ ), backward memory (2 studies, $n=224$, $p=0.08$ ) or information processing (4 studies, $n=309$, $p=0.23$ ) (Supplementary Figure S1).

\section{Youth with ADHD Have Lower Levels of $n$-3 PUFAs}

In the overall meta-analysis, irrespective of tissue source, youth with ADHD have lower levels of DHA (8 studies, $n=486, g=-0.56, p=0.05)$, but no group differences are present for EPA, AA, n-3 PUFAs and n-6 PUFAs levels (Figure 4).

We also performed a secondary analysis by excluding the study by Stevens et al (2003), which was different from all other studies in their participants' inclusion criteria (see Figure 4 and Discussion). In this analysis, we found that youth with ADHD indeed have lower levels not only of DHA (7 studies, $n=412, g=-0.76, p=0.0002$ ), but also of EPA (7 studies, $n=468, g=-0.38, p=0.0008$ ), total $n-3$ (6 studies, $n=396, g=-0.58, p=0.0001)$ and AA (7 studies, $n=493$, $g=-0.41, p<0.0001$ ), but not of $n-6$ PUFAs (7 studies, $n=425, p=0.80$ ) (Figure 4).

We also performed subanalyses looking at levels of the RBCs and plasma PUFAs separately. Youth with ADHD have lower RBCs DHA (5 studies, $n=277, g=-0.77$, $p<0.0001$ ), EPA (4 studies, $n=196, g=-0.55, p=0.01$ ) and $n-3$ PUFAs (4 studies, $n=245, g=-0.70, p=0.0002$ ) (Supplementary Figure S2). However, the subanalysis showed that there is no difference in plasma PUFAs levels (Supplementary Figure S3).

\section{DISCUSSION}

This is the first meta-analysis to examine the roles of $n-3$ PUFAs as both interventions and biomarkers in youth with $\mathrm{ADHD}$, and to separately analyze RBCs and plasma levels of $n$-3 PUFAs in these individuals. We show that $n-3$ PUFAs supplementation improves total ADHD symptoms compared with placebo, with a modest effect size $(g=0.38)$. Moreover, $n$-3 PUFAs also improve omission and commission errors compared with placebo, with a large effect size $(g=1.09$ to 2.14$)$. Finally, youth with ADHD have lower levels of DHA, EPA, $n-3$ PUFAs, and AA than control youth, with moderate to large effect size $(g=-0.38$ to -0.76$)$.

\section{n-3 PUFAs Improve Clinical Symptoms}

n-3 PUFAs supplementation improves clinical symptoms in youth with ADHD in this meta-analysis, measured as parental reports of total $\mathrm{ADHD}$, inattention and hyperactivity symptom scores. In contrast, we found no effects of PUFAs on the teacher-reported ADHD severity (Gustafsson et al, 2010; Manor et al, 2012; Widenhorn-Muller et al, 2014). Parental and teachers' ratings provide unique clinical information regarding ADHD symptoms in different settings, and in general show only weak to moderate correlations (Narad et al, 2015). For example, parents are 


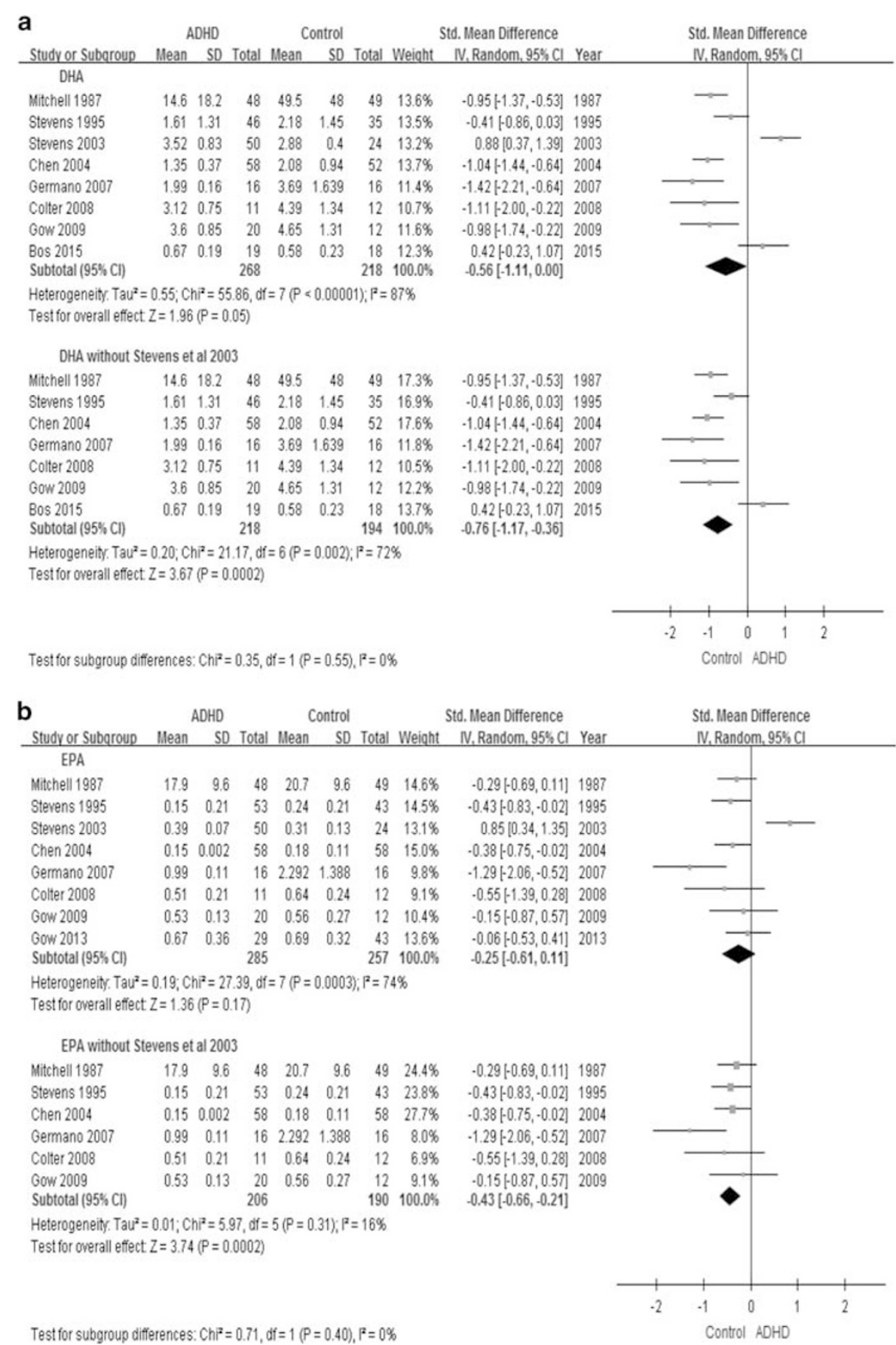

Figure 4 Forest plots showing effect sizes (Hedges's g) and 95\% confidence intervals (Cls) from individual studies and pooled results comparing n-3 PUFAs Levels, (a) DHA, (b) EPA, (c) n-3, (d) AA, (e) n-6, between ADHD population and control group. AA, arachidonic acids; ADHD, attention deficit hyperactivity disorder; $\mathrm{Cl}$, confidence interval; DHA, docosahexaenoic acids; EPA, eicosapentaenoic acids; N3, n-3 or omega-3 polyunsaturated fatty acids; N6, n-6 or omega-6 polyunsaturated fatty acids; Std, standard.

more likely to detect changes in the child's daily activities, such as getting ready for school, getting dressed, getting ready for bed, eating meals, and completing their homework. In contrast, teachers' reports are more representative of the child's behavior at school, such as peer interactions and talking in class. This could explain why only symptoms measured by parental reports seem to improve following treatment with PUFAs. However, it is also important to highlight that the sample size is smaller for studies using teacher reports $(n=344$ with teacher reports $v s n=534-590$ with parental reports), which could also contribute to the negative findings.

The dosage of $n$-3 PUFAs supplementation included in our meta-analysis ranges from 2.7 to $640 \mathrm{mg}$ of DHA and 80 to $650 \mathrm{mg}$ of EPA, with one study using EPA $(560 \mathrm{mg})$ as the sole source of n-3 PUFAs supplementation. Our paper demonstrates that all trials included in the meta-analysis improve inattention and total ADHD symptoms scores, regardless of the EPA supplementation dosage. However, only studies with EPA doses of $>500 \mathrm{mg}$ improve 
c $\begin{array}{lcccc}\text { C ADHD } & \text { Control } & \text { Std. Mean Difference } & \text { Std. Mean Difference } \\ \text { Study or Subaroup Mean SD Total Mean SD Total Weiaht IV. Random. 95\% Cl Year } & \text { IV. Random. 95\% Cl }\end{array}$

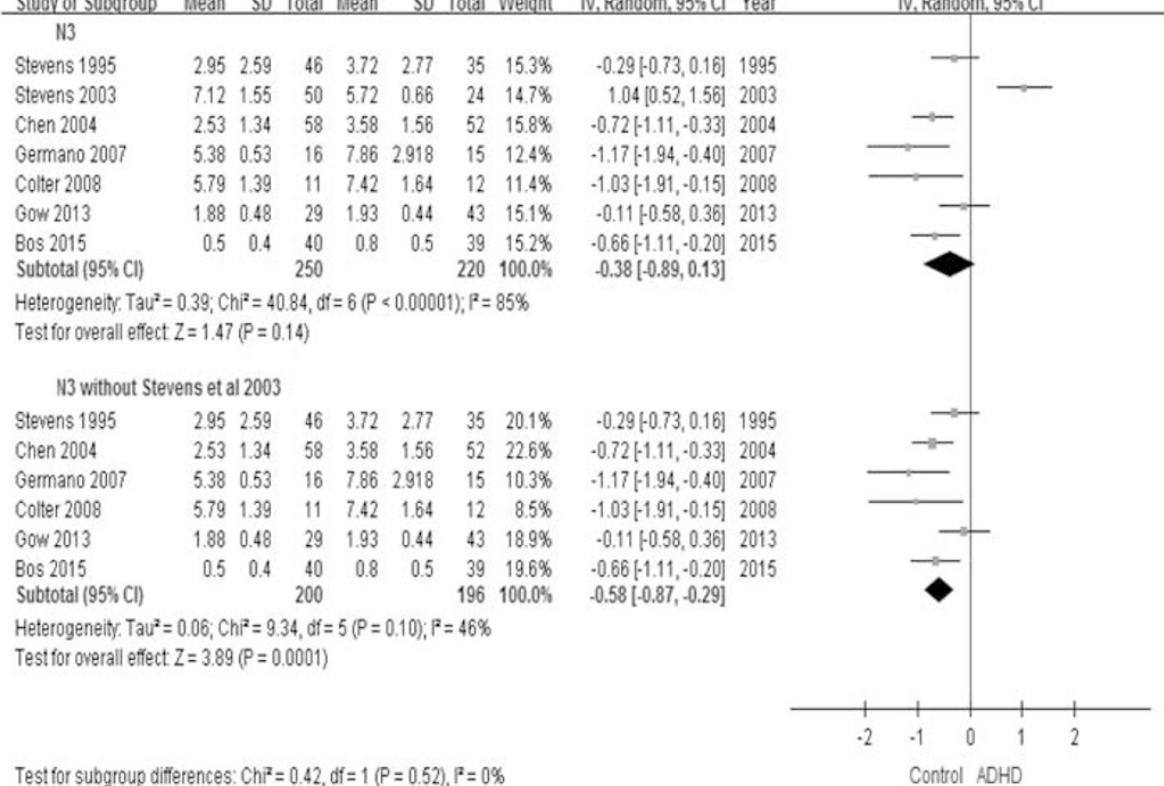

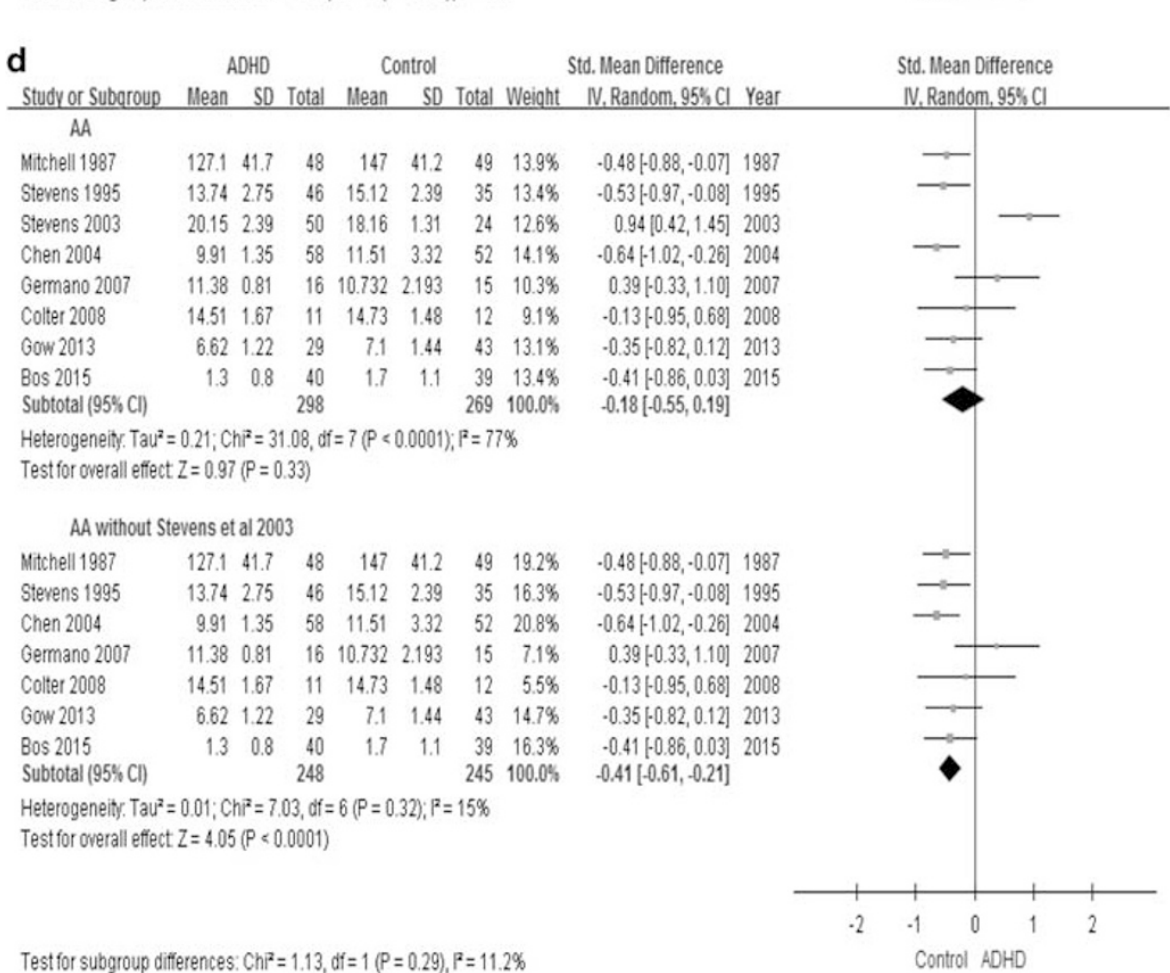

Figure 4 Continued.

hyperactivity symptoms. Thus, our paper shows that EPA supplementation dosage $>500 \mathrm{mg}$ should be considered when treating youth with ADHD, especially those with predominantly hyperactivity/impulsivity presentation.

\section{n-3 PUFAs Improve Cognitive Performance}

The second finding of this meta-analysis is that $n$-3 PUFAs supplementation shows efficacy in improving omission and commission errors, but not memory and information processing, in children with ADHD. This is consistent with epidemiological studies, where EFA deficiency correlates with cognitive impairment and increased impulsivity (associated with commission errors) (Chang et al, 2016). n-3 PUFAs are crucial for optimal neurotransmitter function: for example, incorporating more EPA and DHA in the cell membrane can increase cholesterol efflux (Chang and $\mathrm{Su}$, 2010), modulate lipid raft clustering and disruption (Chang and Su, 2010), and affect the function of the dopamine transporter (DAT; Foster et al, 2008), which in turn may 


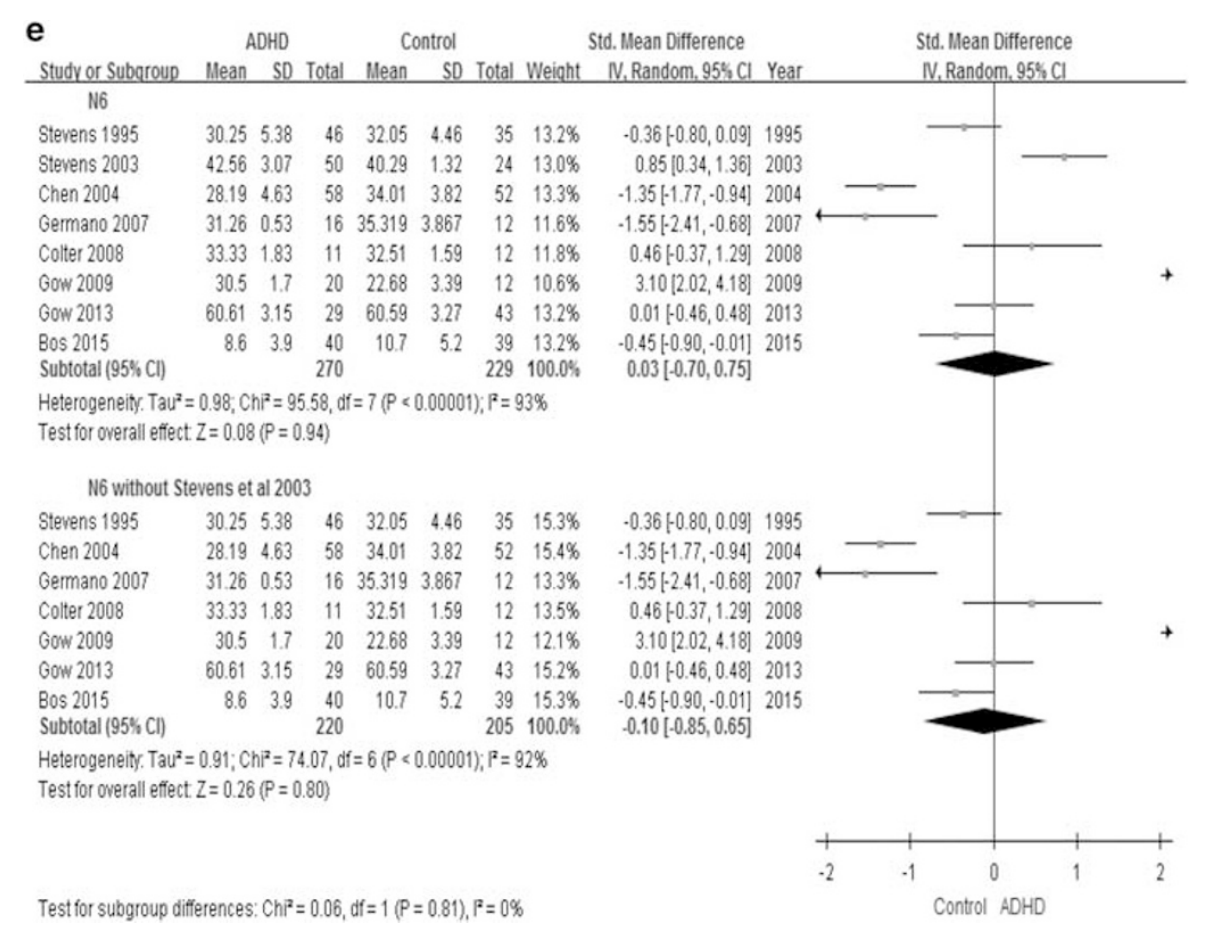

Figure 4 Continued.

affect attention and executive function by regulating synaptic dopamine levels (Foster et al, 2008).

\section{Youth with ADHD Have Lower Levels of $\boldsymbol{n}$-3 PUFAs}

Our overall meta-analysis, including all studies and irrespective of tissue source, shows that youth with ADHD have lower levels of DHA. DHA has been implicated in the brain development of infants and children, since lower maternal intake of $n-3$ PUFAs during pregnancy is associated with worse developmental outcomes in the offspring, including lower fine motor and communication scores and lower social development scores (Hibbeln et al, 2007). Children with developmental disorders also have lower levels of DHA (Milte et al, 2011).

When we excluded the study by Stevens et al (2003) from the meta-analysis, we found that youth with ADHD also have lower EPA, $n-3$ PUFAs and AA levels. In the study by Stevens et al (2003), children with ADHD had higher RBCs levels of AA and DHA when compared with healthy children, which is different from all other studies. We would argue that we are justified to exclude Stevens et al (2003), as in this study the diagnosis of ADHD was not strictly defined, and the subjects self-referred and enrolled in the ADHD group if they reported to have been given a diagnosis of ADHD from a paediatrician, psychologist or psychiatrist. In contrast, in all the other studies the diagnosis was confirmed by standardized clinical interviews, and/or subjects had an ADHD symptoms rating scale score of moderate severity. In fact, the enrolment criteria in Stevens's study (2003) are also different from a previous study from the same authors (Stevens et al, 1995), where the subjects had a clinical diagnosis of ADHD and severity confirmed by the Parent/ Teacher Conner's Rating Questionnaire; and indeed, in this first study they found that ADHD children do have lower levels of plasma and/or RBCs DHA, EPA, $n$-3 PUFAs and AA. Taken together, these lines of evidence justify our decision to present the findings with and without this study (Stevens et al, 2003).

Furthermore, in our meta-analysis youth with ADHD also have lower levels of AA, while no difference in n-6 PUFAs levels were present. AA, derived from linolenic acid, is the precursor of a wide range of biologically and clinically important eicosanoids, incuding prostaglandins, thromboxanes, and leukotrienes; it is also one of the most abundant fatty acids, after DHA, in the brain. Indeed, lower levels of DHA and AA have been associated with more anxiety, impulsivity and hyperactivity symptoms in ADHD (Stevens et al, 1995), while low dose dietary supplementation of AA had been shown to possible improve cognition (Okaichi et al, 2005; Ishikua et al, 2009). The deficiency of AA in ADHD, may be due to a reduced ability to convert linolenic acid to AA (Kinsella et al, 1990; Burgess et al, 2000). Possible steps associated with inefficient conversion include desaturase steps, the manlonyl-CoA-dependent elongation steps, and the peroxisomal $\beta$-oxidation steps (Burgess et al, 2000). Moreover, ratio of linelonic acid to AA was greater in a subgroup of youth with ADHD with a greater severity of EFA deficiency (Burgess et al, 2000). Another explanation for the low AA levels may be an increased metabolism of AA to the eicosanoids via nonenzymatic oxidation, due to impaired cellular defense mechanism (Burgess et al, 2000).

It is also of note that a subanalysis of RBCs levels of $n-3$ PUFAs shows that youth with ADHD have lower levels of RBCs, but not plasma, DHA, EPA, $n-3$ and AA. Both RBCs and plasma PUFAs are common biomarkers used to reflect fatty acid intake/status in clinical studies (Chang et al, 2015; Chang et al, 2017; Lin et al, 2010; Su et al, 2014). Of note, RBCs and plasma PUFAs levels are measured with standard gas chromatography in the studies included in the meta- 
analysis. The units are presented as percentage, which is more reliable in cross-study comparison (Lin et al, 2010; Lin et al, 2017). Although the PUFAs levels from the metaanalysis were not directly from brain tissues, thus the results can not be directly applied to brain tissue PUFAs levels, peripheral RBCs and plasma DHA and EPA levels do highly correlate with brain DHA and EPA levels in animal studies (Connor et al, 1990; Lapillonne et al, 2002; Stark, 2008). In addition, RBCs PUFAs are more strongly correlated with dietary intake (Sun et al, 2007), and reflect longer-term fatty acid consumption (eg, months) (Sun et al, 2007), while plasma PUFAs reflect recent fluctuations of fatty acid consumptions (eg, days). We also included buccal cells PUFAs measurements, a non-invasive measurement that correlates significantly with RBCs, plasma and brain PUFAs (Lapillonne et al, 2002). However, since only one study (Bos et al, 2015) in the meta-analysis used buccal cells PUFAs measurement, more studies using this method will be needed to support its role as a biomarker.

\section{Biological Mechanisms and Clinical Impact}

EPA is the most common form of fatty acids stored in our body, and will convert to DHA when needed, thus the low EPA level identified in the meta-analysis may indicate an attempt of the body to compensate for the low DHA levels. DHA is crucial for neurodevelopment, and its supplementation has been associated with learning (Milte et al, 2011). In contrast, EPA have been associated with mood regulation (Lin et al, 2010), and EPA supplementation has stronger antidepressant effects than DHA (Su et al, 2014), although higher DHA and EPA levels are both associated with lower anxiety and shyness (Milte et al, 2011).

In the context of 'personalized medicine', it is tempting to speculate that a subpopulation of youth with ADHD and with low levels of $n$-3 PUFAs may respond better to $n$-3 PUFAs supplementation, but there are no studies to date attempting this stratification approach. However, we have shown that individuals at genetic risk of developing depression in the context of the immune challenge, interferon-alpha (IFN- $\alpha$ ), have lower levels of RBCs n3-PUFAs (Su et al, 2010), and that $n$-3 PUFAs supplementation prevents the onset of IFN- $\alpha$-induced depression, arguably by replenishing the endogenously low antiinflammatory PUFAs in the 'at risk' individuals ( $\mathrm{Su}$ et al, 2014). Moreover, a recent study by Rapaport has stratified patients with major depressive disorder into a 'high' and a 'low' inflammation group, and shown that the 'high inflammation' group has a better responses to EPA (Rapaport et al, 2016). Indeed, some studies have found inflammatory abnormalities in ADHD, and this would support the theoretical model that PUFAs affect ADHD symptoms via an anti-inflammatory action ( $\mathrm{Su}$ et al, 2014). For example, one study has shown that ADHD children have higher IL-6 and IL-10 levels (Donfrancesco et al, 2016), while another study has shown that $n-3$ supplementation in ADHD children reduces IL-6 and C-reactive protein (CRP) levels (Hariri et al, 2012). Therefore, stratification of ADHD children by $n$-3 PUFAs levels or by immune biomarkers could be one approach to optimize the therapeutic effects of $n$-3 PUFAs supplementation.

\section{Limitations and Conclusions}

This meta-analysis is limited by paucity of original data in some of the investigated comparisons. For example, all studies examining efficacy in clinical symptoms had parental, but only some had teacher, ratings of ADHD symptoms. Similarly, fewer studies measured memory function and information processing, which again may have contributed to the negative findings. The other limitation is that there are no actual data linking DHA/EPA baseline levels and EPA/ DHA concentrations after treatment and response. Another limitation is that some of our analyses have been conducted only on 2-3 studies, which is not ideal for meta-analysis. Nevertheless, the conclusions remain reliable in that we have conducted the systematic review and meta-analyses in accordance with the Preferred Reporting Items for Systematic Reviews and Meta-analysis (PRISM) guidelines. Moreover, supporting literature has suggested that two studies are adequate to perform a meta-analysis (Valentine et al, 2010). Finally, our decision to exclude Stevens's study (2003), extensively discussed above, is scientifically justified, but does partly contravene the meta-analysis model. Notwithstanding these limitations, however, we provide strong evidence supporting a role for n3-PUFAs deficiency in ADHD, and for advocating $n-3$ PUFAs supplementation as a clinically relevant intervention in this group, especially if guided by a biomarker-based personalisation approach.

\section{FUNDING AND DISCLOSURE}

The work was supported by the following grants: MOST 1052918-I-039-001, 104-2314-B-039-050-MY3, 104-2314-B-039022-MY2, 103-2923-B-039-002-MY3, 103-2320-B-039-036, from Ministry of Science and Technology; and China Medical University under the Aim for Top University Plan of Ministry of Education, Taiwan. CMP and VM are also supported by the grants 'Immunopsychiatry: a consortium to test the opportunity for immunotherapeutics in psychiatry' (MR/L014815/1) and 'Persistent Fatigue Induced by Interferon-alpha: A New Immunological Model for Chronic Fatigue Syndrome' (MR/J002739/1), from the Medical Research Council (UK), and by the National Institute for Health Research Mental Health Biomedical Research Centre in Mental Health at South London and Maudsley NHS Foundation Trust and King's College London (UK). JPC has received speaker's fee and consultation fees from Janssen Pharmaceutical Companies of Johnson \& Johnson and Eli Lilly and Company. CMP and VM have received research funding from Janssen Pharmaceutical NV/Janssen Pharmaceutical Companies of Johnson\&Johnson. CMP has also received speaker's fees from Lundbeck and consultation fees from Consultant to Eleusis Benefit Corporation. The remaining author declares no conflict of interest.

\section{REFERENCES}

Barkley RA (1997). Behavioral inhibition, sustained attention, and executive functions: constructing a unifying theory of ADHD. Psychol Bull 12: 65-94.

Bos DJ, Oranje B, Veerhoek E, Van Diepen RM, Weusten JM, Demmelmair $\mathrm{H}$ et al (2015). Reduced symptoms of inattention after dietary omega-3 fatty acid supplementation in boys with and 
without attention deficit/hyperactivity disorder. Neuropsychopharmacology 40: 2298-2306.

Burgess JR, Stevens L, Zhang W, Peck L (2000). Long-chain polyunsaturated fatty acids in children with attention-deficit hyperactivity disorder. Am J Clin Nutr 17(suppl): 327S-330S.

Chang JP, Chang SS, Yang HT, Palani M, Chen CP, Su KP (2015). Polyunsaturated fatty acids (PUFAs) levels in patients with cardiovascular diseases (CVDs) with and without depression. Brain Behav Immun 44: 28-31.

Chang JP, Jiling L, Huang YT, Lu YJ, Su KP (2016). Delay aversion, temporal processing, and N-3 fatty acids intake in childrne with attention- deficit/hyperactivity disorder (ADHD). Clin Psychol 4: 1094-1103.

Chang JP, Lai HC, Yang HT, Su WP, Peng CY, Galecki P et al (2017). Polyunsaturated fatty acids levels and initial presentation of somatic symptoms induced by interferon-alpha therapy in patients with chronic hepatitis C viral infection. Nutr Neurosci 20: 291-296.

Chang JP, Su KP (2010). The lipid raft hypothesis: the relation among omega-3 fatty acids, depression, and cardiovascular diseases. Taiwan J Psychiatry 24: 168-180.

Chen JR, Hsu SF, Hsu CD, Hwang LH, Yang SC (2004). Dietary patterns and blood fatty acid composition in children with attention-deficit hyperactivity disorder in Taiwan. J Nutr Biochem 15: 467-472.

Chiu CC, Su KP, Cheng TC, Liu HC, Chang CJ, Dewey ME et al (2008). The effects of omega-3 fatty acids monotherapy in Alzheimer's disease and mild cognitive impairment: a preliminary randomized double-blind placebo-controlled study. Prog Neuropsychopharmacol Biol Psychiatry 32: 1538-1544.

The Cochrane Collaboration (2014). Review Manager (RevMan) [Computer program]: Version 5.3. Copenhagen: The Nordic Cochrane Centre.

Colter AL, Cutler C, Meckling KA (2008). Fatty acid status and behavioural symptoms of attention deficit hyperactivity disorder in adolescents: A case-control study. Nutr J 7: 8.

Connor WE, Neuringer M, Lin DS (1990). Dietary effects on brain fatty acid composition: the reversibility of n-3 fatty acid deficiency and turn-over of docosahexaenoic acid in the brain, erythrocytes, and plasma of rhesus monkeys. J Lipid Res 31: 237-247.

Cooper RE, Tye C, Kuntsi J, Vassos E, Asherson P (2015). Omega-3 polyunsaturated fatty acid supplementation and cognition: a systematic review and meta-analysis. J Psychopharmacol 29: 753-763.

Das UN (2006). Essential fatty acids: biochemistry, physiology and pathology. Biotechnol J 1: 420-439.

Donfrancesco R, Nativio P, Borrelli E, Giua E, Andriola E, Villa MP et al (2016). Serum cytokines in paediatric neuropsychiatric syndromes: focus on attention deficit hyperactivity disorder. Minerva Pediatr Epub ahead of print.

Foster JD, Adkins SD, Lever JR, Vaughan RA (2008). Phorbol ester induced trafficking-independent regulation and enhanced phosphorylation of the dopamine transporter associated with membrane rafts and cholesterol. J Neurochem 105: 1683-1699.

Germano M, Meleleo D, Montorfano G, Adorni L, Negroni M, Berra B et al (2007). Plasma, red blood cells phospholipids and clinical evaluation after long chain omega-3 supplementation in children with attention deficit hyperactivity disorder (ADHD). Nutr Neurosci 10: 1-9.

Gillies D, Sinn J, Lad SS, Leach MJ, Ross MJ (2012). Polyunsaturated fatty acids (PUFA) for attention deficit hyperactivity disorder (ADHD) in children and adolescents. Cochrane Database Syst Rev CD007986.

Gow RV, Matsudaira T, Taylor E, Rubia K, Crawford M, Ghebremeskel K et al (2009). Total red blood cell concentrations of omega-3 fatty acids are associated with emotion-elicited neural activity in adolescent boys with attention-deficit hyperactivity disorder. Prostaglandins Leukot Essent Fatty Acids 80: $151-156$.

Gow RV, Vallee-Tourangeau F, Crawford MA, Taylor E, Ghebremeskel K, Bueno AA et al (2013). Omega-3 fatty acids are inversely related to callous and unemotional traits in adolescent boys with attention deficit hyperactivity disorder. Prostaglandins Leukotr Essent Fatty Acids 88: 411-418.

Gustafsson PA, Birberg-Thornberg U, Duchen K, Landgren M, Malmberg K, Pelling $\mathrm{H}$ et al (2010). EPA supplementation improves teacher-rated behaviour and oppositional symptoms in children with ADHD. Acta Paediatrica 99: 1540-1549.

Hariri M, Djazayery A, Djalali M, Saedisomeolia A, Rahimi A, Abdolahian E (2012). Effect of $n-3$ supplementation on hyperactivity, oxidative stress and inflammatory mediators in children with attention-deficit-hyperactivity disorder. Malays J Nutr 18: 329-335.

Hawkey E, Nigg JT (2014). Omega-3 fatty acid and ADHD: blood level analysis and meta-analytic extension of supplementation trials. Clin Psychol Rev 34: 496-505.

Hibbeln JR, Davis JM, Steer C, Emmett P, Rogers I, Williams C et al (2007). Maternal seafood consumption in pregnancy and neurodevelopmental outcomes in childhood (ALSPAC study): an observational cohort study. Lancet 369: 578-585.

Ishikua $\mathrm{Y}$, Ikeda $\mathrm{G}$, Akimoto $\mathrm{K}$, Hata $\mathrm{M}$, Kusumoto $\mathrm{A}$, Kidokoro A et al (2009). Arachidonic acid supplementation decreased P300 latency and increases P300 amplitude of eventrelated potentioals in healthy elderly men. Neuropsychobiology 60: 73-79.

Kinsella JE, Broughton KS, Whelan JW (1990). Dietary unsaturated fatty acid: interactions and possible needs in relation to eicosanoids synthesis. J Nutr Biochem 9: 123-141.

Lapillonne A, DeMar JC, Nannegari V, Heird WC (2002). The fatty acid profile of buccal cheek cell phospholipids is a noninvasive marker of long-chain polyunsaturated fatty acid status in piglets. J Nutr 132: 2319-2323.

Lin PY, Chang CH, Chong MF, Chen H, Su KP (2017). Polyunsaturated fatty cids in perinatal depression: a systematic review and meta-analysis. Biol Psychiatry Epub ahead of print.

Lin PY, Huang SY, Su KP (2010). A meta-analytic review of polyunsaturated fatty acid compositions in patients with depression. Biol Psychiatry 68: 140-147.

Lin PY, Su KP (2007). A meta-analytic review of double-blind, placebo-controlled trials of antidepressant efficacy of omega-3 fatty acids. J Clin Psychiatry 68: 1056-1061.

Manor I, Magen A, Keidar D, Rosen S, Tasker H, Cohen T et al (2012). The effect of phosphatidylserine containing Omega3 fattyacids on attention-deficit hyperactivity disorder symptoms in children: a double-blind placebo-controlled trial, followed by an open-label extension. Eur Psychiatry 27: 335-342.

Milte CM, Sinn N, Buckley JD, Coates AM, Young RM, Howe PR (2011). Polyunsaturated fatty acids, cognition and literacy in children with ADHD with and without learning difficulties. J. Child Health Care 15: 299-311.

Mitchell EA, Aman MG, Turbott SH, Manku M (1987). Clinical characteristics and serum essential fatty acid levels in hyperactive children. Clin Pediatr (Phila) 26: 406-411.

Moher D, Liberati A, Tetzlaff J, Altman DG (2009). Preferred reporting items for systematic reviews and meta-analyses: the PRISMA statement. J Clin Epidemiol 62: 1006-1012.

Narad ME, Garner AA, Peugh JL, Tamm L, Antonini TN, Kingery KM et al (2015). Parent-teacher agreement on ADHD symptoms across development. Psychol Assess 27: 239-248.

Okaichi Y, Ishikua Y, Akimoto K, Kawashima H, Toyoda-Ono Y, Kiso $Y$ et al (2005). Arachidonic acid improves aged rats' spatial cognition. Physiol Behav 84: 617-623.

Perera H, Jeewandara KC, Seneviratne S, Guruge C (2012). Combined omega 3 and omega6 supplementation in children with attention-deficit hyperactivity disorder (ADHD) refractory 
to methylphenidate treatment: A double-blind, placebo-controlled study. J Child Neurol 27: 747-753.

Pliszka SR, Crismon ML, Hughes CW, Corners CK, Emslie GJ, Jensen PS et al (2006). The Texas Children's Medication Algorithm Project: revision of the algorithm for pharmacotherapy of attention-deficit/hyperactivity disorder. J Am Acad Child Adolesc Psychiatry 45: 642-657.

Puri BK, Martins JG (2014). Which polyunsaturated fatty acids are active in children with attention-deficit hyperactivity disorder receiving PUFA supplementation? A fatty acid validated metaregression analysis of randomized controlled trials. Prostaglandins Leukot Essent Fatty Acids 90: 179-189.

Quintana H, Cherlin EA, Duesenberg DA, Bangs ME, Ramsey JL, Feldman PD et al (2007). Transition from methylphenidate or amphetamine to atomoxetine in children and adolescents with attention-deficit/hyperactivity disorder-a preliminary tolerability and efficacy study. Clin Ther 29: 1168-1177.

Rapaport MH, Nierenberg AA, Schettler PJ, Kinkead B, Cardoos A, Walker R et al (2016). Inflammation as a predictive biomarker for response to omega-3 fatty acids in major depressive disorder: a proof-of-concept study. Mol Psychiatry 21: 71-79.

Richardson AJ, Puri BK (2002). A randomized double-blind, placebo-controlled study of the effects of supplementation with highly unsaturated fatty acids on ADHD-related symptoms in children with specific learning difficulties. Progress Neuropsychopharmacol Biol Psychiatry 26: 233-239.

Shadish WR (1994). Combining estimates of the effect size. In: Cooper HH, LV (eds) The Handbook of Research Synthesis. Russell Sage Foundation: New York. pp 261-281.

Sinn N, Bryan J, Wilson C (2008). Cognitive effects of polyunsaturated fatty acids in children with attention deficit hyperactivity disorder symptoms: a randomised controlled trial. Prostaglandins Leukot Essent Fatty Acids 78: 311-326.

Sonuga-Barke EJ, Brandeis D, Cortese S, Daley D, Ferrin M, Holtmann $M$ et al (2013). Nonpharmacological interventions for ADHD: systematic review and meta-analyses of randomized controlled trials of dietary and psychological treatments. Am J Psychiatry 170: 275-289.

Stark KD (2008). The percentage of n-3 highly unsaturated fatty acids in total HUFA as biomarker for omega- 3 fatty acid status in tissues. Lipids 43: 45-53.

Stata Corp. Stata Statistical Software: Release 11. StataCorp LP: College Station, TX, USA, 2009.

Stevens L, Zhang W, Peck L, Kuczek T, Grevstad N, Mahon A et al (2003). EFA supplementation in children with inattention, hyperactivity, and other disruptive behaviors. Lipids 38: 1007-1021.

Stevens LJ, Zentall SS, Deck JL, Abate ML, Watkins BA, Lipp SR et al (1995). Essential fatty-acid metabolism in boys with attention-deficit hyperactiviyt disorder. American J Clin Nutr 62: $761-768$.

Su KP, Huang SY, Chiu CC, Shen WW (2003). Omega-3 fatty acids in major depressive disorder. A preliminary double-blind, placebo-controlled trial. Eur Neuropsychopharmacol 13: 267-271.

Su KP, Huang SY, Chiu TH, Huang KC, Huang CL, Chang HC et al (2008). Omega-3 fatty acids for major depressive disorder during pregnancy: results from a randomized, double-blind, placebocontrolled trial. J Clin Psychiatry 69: 644-651.

Su KP, Huang SY, Peng CY, Lai HC, Huang CL, Chen YC et al (2010). Phospholipase A2 and cyclooxygenase 2 genes influence the risk of interferon-alpha-induced depression by regulating polyunsaturated fatty acids levels. Biol Psychiatry 67: 550-557.

Su KP, Lai HC, Yang HT, Su WP, Peng CY, Chang JP et al (2014). Omega-3 fatty acids in the prevention of interferon-alphainduced depression: results from a randomized, controlled trial. Biol Psychiatry 76: 559-566.

Sun Q, Ma J, Campos H, Hankinson SE, Hu FB (2007). Comparison between plasma and erythrocyte fatty acid content as biomarkers of fatty acid intake in US women. Am J Clin Nutr 86: 74-81.

The MTA Cooperative Group (1999). A 14-month randomized clinical trial of treatment strategies for attention-deficit/hyperactivity disorder. Arch Gen Psychiatry 56: 1073-1086.

Vaisman N, Kaysar N, Zaruk-Adasha Y, Pelled D, Brichon G, Zwingelstein $\mathrm{G}$ et al (2008). Correlation between changes in blood fatty acid composition and visual sustained attention performance in children with inattention: effect of dietary n-3 fatty acids containing phospholipids. Am J Clin Nutr 87: 1170-1180.

Valentine JC, Pigott TD, Rothstein HR (2010). How many studies do you need? A primer on statistical power for meta-analysis. J Educ Behav Stat 35: 215-247.

Voigt RG, Llorente AM, Jensen CL, Fraley JK, Berretta MC, Heird WC (2001). A randomized, double-blind, placebo-controlled trial of docosahexaenoic acid supplementation in children with attention-deficit/hyperactivity disorder. J Pediatr 139: 189-196.

Widenhorn-Muller K, Schwanda S, Scholz E, Spitzer M, Bode H (2014). Effect of supplementation with long-chain omega-3 polyunsaturated fatty acids on behavior and cognition in children with attention deficit/hyperactivity disorder (ADHD): A randomized placebo-controlled intervention trial. Prostaglandins Leukot Essent Fatty Acids 91: 49-60.

Supplementary Information accompanies the paper on the Neuropsychopharmacology website (http://www.nature.com/npp) 